http://dx.doi.org/10.5050/KSNVE.2012.22.9.825

$$
\text { 도심지역에 서식하는 매미 울음소리의 음질 특성 }
$$

\title{
Sound Quality Characteristics of the Cicada Singing Noise in Urban Areas
}

$$
\begin{gathered}
\text { 구 진 회†.이 재 원*.이 우 석*.최 경 희*.서 충 열*. } \\
\text { 박 형 규*.김 삼 수*. 한 진 석* }
\end{gathered}
$$

Jinhoi Gu, Jaewon Lee, Woo-Seok Lee, Kyunghee Choi, Chungyoul Seo, Hyungkyu Park, Samsoo Kim and Jinseok Han

(2012년 5월 18일 접수 ; 2012년 6월 7일 심사완료)

Key Words : Cicada Singing Noise(매미 소리), Sound Quality(음질), Time-frequency Analysis(시간-주파수분 석), STFT(Short Time Fourier Transform)

\begin{abstract}
The global warming caused the changes of our environment like an increasing tropical night phenomenon in the middle latitude areas. Especially, in Korea, the habitats of tropical Korean blockish cicada have changed from Jeju island located in Southern part of Korea to the whole of Korea because of the increasingly warming weather. The cicadas crying sound have been social problem because the tropical Korean blockish cicadas cry at middle of the night owing to the various outdoor lights. The cicada is positive phototaxis insect. So, the cicada is not cry at night. But if the outdoor light is very bright, then the cicada confuse the night as a day and start to cry. As a result, the cicadas crying noise has caused the resident living in downtown to an unpleasure and sleeplessness. In this research, we have measured three kinds of cicada singing noise at 16 points of urban area(Incheon, Gwangju, Busan, Gyeonggido Anyang). And then we analyzed the sound quality of the three kinds of cicada singing noise using by CADA-X signal process program. And we analyzed the acoustical characteristics by STFT(short time Fourier transform) which is a time-frequency analysis method. The characteristics of the cicada singing noise in terms of the sound quality and the time-frequency variation will be usefull to discover the relations between the human annoyance about the cicada singing noise and the acoustical characteristics.
\end{abstract}

\section{1. 서 론}

지구온난화로 인한 기후변화로 생태계에는 많은

† 교신저자; 정회원, 국립환경과학원

E-mail : gujhgujh@korea.kr

Tel : (032)560-8323

* 국립환경과학원

\# 이 논문의 일부는 2010년 추계 소음진동 학술대회에서 발표되어 우수논문으로 추천되었음.
변화가 일어나고 있으며 이에 따라 우리를 둘러싼 생활환경에도 여러 가지 변화가 발생하고 있다. 그 러한 변화의 일환으로 지구온난화로 여름철 기온이 상승하자 제주도에만 일부 서식했던 남방계열의 매 미종인 말매미가 국내 수도권과 신도시를 중심으로 정착하면서 그 개체수가 크게 증가하고 있다.

말매미는 현재 국내 서식하는 매미종 중 가장 몸 집이 크고 울음소리가 큰 종으로 시골지역과 달리 도시지역에서는 조류외에 특별한 천적이 없어 그 개체수가 점점 증가하고 있으며 도시지역 매미 개 
체수 증가는 생활환경에서의 매미 소음 증가와 직 결되어 최근에는 ‘매미젤라' 라는 말이 생길정도로 사회적으로도 관심을 불러일으키고 있다. 특히 야간 에 가로등과 같은 인공 조명시설의 불빛 영향으로 야간에도 울어대는 매미 소리는 불쾌감, 불면증, 수 험행 학습방해 등을 일으키는데 이는 더 이상 매미 울음소리가 자연의 소리가 아닌 새로운 생활소음원 으로 부각되는 이유이다.

따라서, 이 연구에서는 도시지역 매미 울음소리에 대한 시간-주파수 분석과 음질 분석을 통해 매미 울음소리의 음향학적 특성과 음질 특성을 규명하여 향후 사람이 매미 울음소리를 소음으로 느끼는 정 도를 평가하는 매미소음 음질평가지표 개발을 위한 기초자료로 활용하고자 한다.

\section{2. 매미 울음소리의 측정}

\section{1 조사대상 매미 선정}

여름절 매미소음은 주로 야간 조명이 많이 설치되 어 있는 대도시에서 크게 발생하는 점을 고려하여 인천, 광주, 부산, 경기도(안양) 등 도심지 주거지역 16 개 지점의 주.야간 매미소음도를 조사하였다. 조사 지역(16개 지점)에 서식하는 매미종을 조사한 결과, 말매미는 16 개 지점, 참매미는 3 개 지점, 쓰름매미는 1 개 지점에서 서식하는 것으로 나타나 도심지 주거 지역에 분포하는 매미는 대부분 말매인 것으로 조사 되었다. 따라서, 이 연구에서는 조사대상 매미종으로 말매미, 참매미, 쓰름매미를 선정하였다.

\section{2 매미 울음소리의 측정}

매미 울음소리의 측정은 Head Acoustics社의 Artificial Head 장비를 이용하여 Fig. 1과 같이 도심지

Table 1 Investigation subjects(three kinds of cicada)

\begin{tabular}{|c|c|c|c|}
\hline $\begin{array}{l}\text { Kinds of } \\
\text { cicada }\end{array}$ & $\begin{array}{c}\text { Korean } \\
\text { blockish cicada }\end{array}$ & Robust cicada & $\begin{array}{l}\text { Meimuna } \\
\text { mongolica }\end{array}$ \\
\hline Appearance & & & \\
\hline Size $(\mathrm{cm})$ & 45 & 36 & 31 \\
\hline
\end{tabular}

주거지역을 중심으로 측정하였다. 매미 울음소리 측 정 시 측정지점이 야외라는 점을 고려하여 측정환경 조건을 자유음장(free field)으로 하고, 순간 최대 매 미 울음소리 크기 $(95 \mathrm{~dB})$ 를 고려하여 최대신호진폭 (dynamic range)을 $104 \mathrm{~dB}$ 로 했으며, 측정지점은 주 변에 반사체와 같은 장애물이 없는 곳으로 선정했다.

\section{3. 매미 울음소리의 측정결과}

\section{1 매미종별 울음소리 크기 비교}

매미종별 울음소리 크기는 말매미가 평균 75.0 $\mathrm{dBA}(1$ 마리당)로 쓰름매미(평균 $67.1 \mathrm{dBA})$ 와 참매미 (평균 $65.2 \mathrm{dBA}$ )보다 $8 \sim 10 \mathrm{dBA}$ 가량 큰 것으로 조 사되었다.

\section{2 주.야간 매미소음 크기 비교}

매미가 우는 지역의 주.야간 매미소음은 주간 평균 $77.8 \mathrm{dBA}$, 야간 평균 $72.7 \mathrm{dBA}$ 로 나타나 주간뿐만 아니라 야간에도 매미소음이 평균 $70 \mathrm{dBA}$ 가 넘는 등 높은 수준으로 나타났다 ${ }^{(1)}$. 이는 조사대상 지역의 도 로변 자동차 주행소음이 평균 $67.9 \mathrm{dBA}$ 임을 감안할 때, 도로변 자동차 주행소음보다 큰 수준이다. 또한,

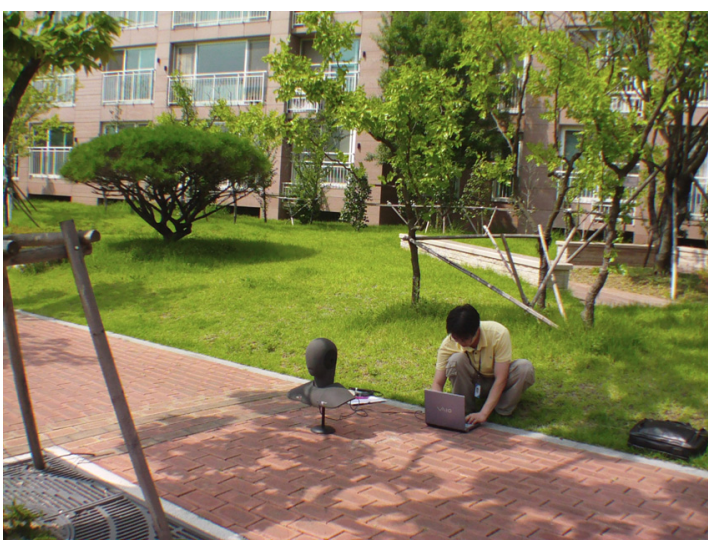

Fig. 1 The measurement of the cicada singing noise

Table 2 Compare the three kinds of cicada singing noise

\begin{tabular}{c|c|c|c}
\hline \hline Kinds of cicada & $\begin{array}{c}\text { Korean } \\
\text { blockish } \\
\text { cicada }\end{array}$ & $\begin{array}{c}\text { Robust } \\
\text { cicada }\end{array}$ & $\begin{array}{c}\text { Meimuna } \\
\text { mongolica }\end{array}$ \\
\hline SPL(average) & 75.0 & 65.2 & 67.1 \\
\hline Range of SPL & $62.8 \sim 80.7$ & $58.8 \sim 67.1$ & $63.1 \sim 70.7$ \\
\hline
\end{tabular}


Table 3 Compare the cicada singing noise at daytime and night

\begin{tabular}{c|c|c|c|c}
\hline \hline $\begin{array}{c}\text { Kinds of } \\
\text { cicada }\end{array}$ & $\begin{array}{c}\text { Korean } \\
\text { blockish } \\
\text { cicada }\end{array}$ & $\begin{array}{c}\text { Robust } \\
\text { cicada }\end{array}$ & $\begin{array}{c}\text { Meimuna } \\
\text { mongolica }\end{array}$ & $\begin{array}{c}\text { All } \\
\text { cicadas }\end{array}$ \\
\hline $\begin{array}{c}\text { Average } \\
\text { SPL at } \\
\text { daytime }\end{array}$ & 81.3 & 69.0 & 67.1 & 77.8 \\
\hline $\begin{array}{c}\text { Range of } \\
\text { SPL in the } \\
\text { daytime }\end{array}$ & $79.3 \sim 82.6$ & $65.0 \sim 72.9$ & $63.1 \sim 70.7$ & $62.8 \sim 82.6$ \\
\hline $\begin{array}{c}\text { Average } \\
\text { SPL at } \\
\text { night }\end{array}$ & 74.3 & 69.5 & - & 72.7 \\
\hline $\begin{array}{c}\text { Range of } \\
\text { SPL at } \\
\text { night }\end{array}$ & $72.7 \sim 75.9$ & 69.5 & - & $69.5 \sim 75.9$ \\
\hline
\end{tabular}

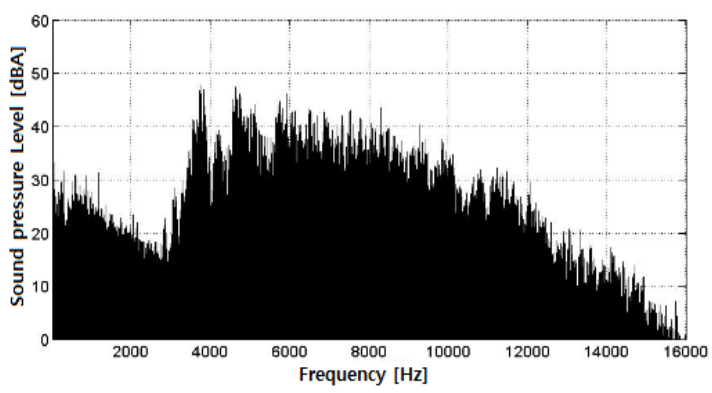

(a) Korean blockish cicada

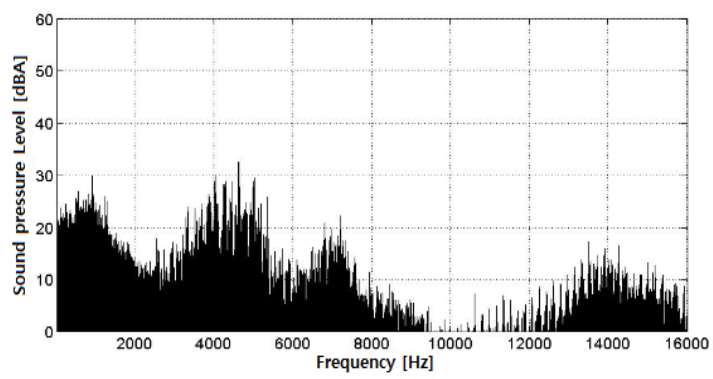

(b) Robust cicada

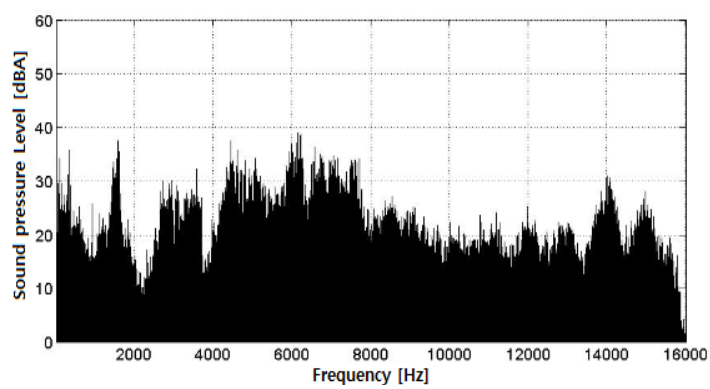

(c) Meimuna mongolica

Fig. 2 The frequency analysis of the 3 kinds of cicada singing noise
야간에 매미가 우는 지점의 가로등 아래 조도는 153 $\sim 2121 \mathrm{x}$, 울지 않는 지점은 52.7 123 1x로 나타나 야 간에 인공조명으로 지나치게 밝은 지점에서 매미가 우는 것으로 조사되었다 ${ }^{(4)}$.

\section{4. 매미 울음소리의 음향학적 특성}

\section{1 매미 울음소리의 주파수 분석}

말매미, 참매미, 쓰름매미 울음소리의 주파수 분 석 결과 말매미는 $4,000 \mathrm{~Hz}$ 이상의 고주파 영역에 큰 소음성분이 분포하는 것으로 나타났고 참매미는 고주파 영역의 소음성분이 작은 것으로 나타났으며 쓰름매미는 전체적으로 고루 소음성분이 분포하는 것으로 나타났다. 이는 음질값 중 샤프니스가 고주 파 소음 성분의 크기에 따라 커지는 것(2)을 고려할 때, 음질분석 결과 말매미의 샤프니스가 가장 크고 다음 쓰름매미, 참매미 순으로 높게 나온 결과와도 일치한다. Fig. 2는 말매미, 참매미, 쓰름매미 울음 소리의 주파수 분석 결과를 나타낸다.

\section{2 매미 울음소리의 시간-주파수 분석}

Fig. 3은 말매미, 참매미, 쓰름매미 울음소리의 STFT(short time Fourier transform) ${ }^{(3)}$ 을 이용한 시 간-주파수 분석 결과를 나타낸다. 말매미와 쓰름매 미 소리는 시간에 따른 주파수 변화가 거의 없는 것 으로 나타났지만 참매미 소리는 시간에 따라 매미 울음소리 크기 및 주파수 성분이 반복적으로 변하는 특성(저주파 소음과 고주파 소음 강도가 반복적으로 커지다가 작아짐)이 있는 것으로 나타났다. 이는 참 매미의 음질값 중 변동강도(fluctuation strength) 성분 이 커지는데 영향을 주며 참매미의 음질 분석 결과 변동강도가 가장 크게 나타난 결과와도 일치한다. 쓰 름매미 역시 주기적으로 매미 울음소리가 크기 및 주파수 성분이 변하여 매미 울음소리의 음질 값 중 변동강도 성분이 말매미에 비해 크게 나타났다.

\section{5. 매미 울음소리의 음질 특성}

\section{1 매미 울음소리의 음질 분석}

말매미, 참매미, 쓰름매미의 울음소리에 대한 음질 분석은 신호처리 상용프로그램인 CADA-X의 Test Monitor를 이용하여 소리의 라우드니스(주관적크기), 샤프니스(날카로움), 러프니스(거칠기), 변동강도(변동 


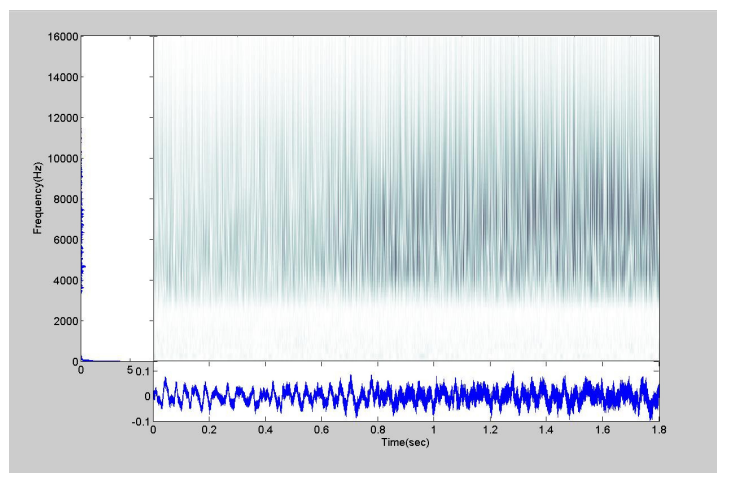

(a) Korean blockish cicada

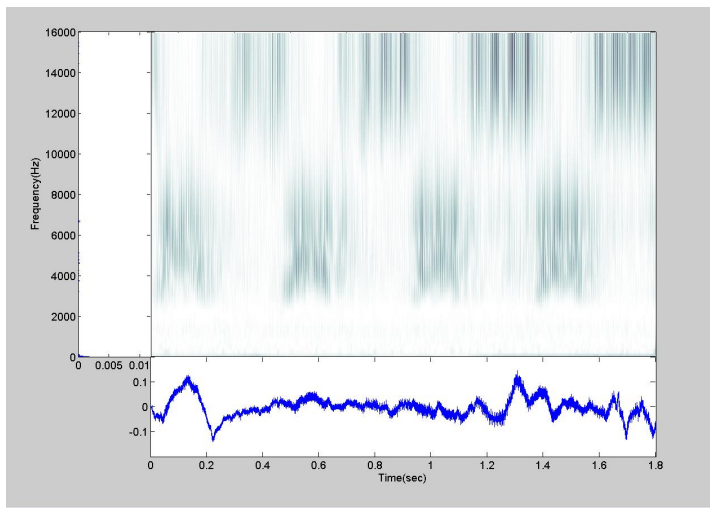

(b) Robust cicada

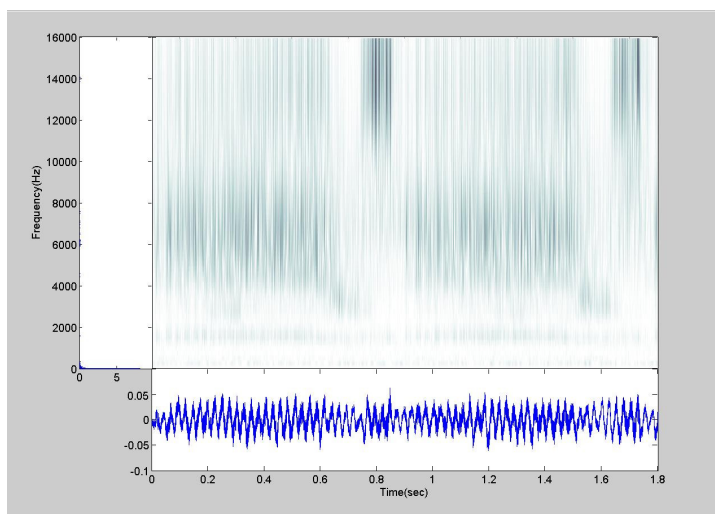

(c) Meimuna mongolica

Fig. 3 The time-frequency analysis of the 3 kinds of cicada singing noise

성)를 분석했다(2). 매미 울음소리에 대한 음질분석 결과, 말매미는 라우드니스가 24.83 sone로 가장 크 고, 샤프니스도 $3.37 \mathrm{acum}$ 으로 가장 크며, 러프니스 도 0.080 asper로 가장 크게 나타나 말매미 울음소 리가 크기도 하지만 가장 날카롭고 거칠어 다른
Table 4 The sound quality of the 3 kinds of cicada singing noise

\begin{tabular}{c|c|c|c|c|c}
\hline \hline $\begin{array}{c}\text { Kinds of } \\
\text { cicada }\end{array}$ & $\mathrm{dBA}$ & $\begin{array}{c}\text { Loudness } \\
\text { (sone) }\end{array}$ & $\begin{array}{c}\text { Sharpness } \\
\text { (acum) }\end{array}$ & $\begin{array}{c}\text { Roughness } \\
\text { (asper) }\end{array}$ & $\begin{array}{c}\text { Fluctuation } \\
\text { strength } \\
\text { (vacil) }\end{array}$ \\
\hline $\begin{array}{c}\text { Korean } \\
\text { blockish } \\
\text { cicada }\end{array}$ & 73.0 & 24.83 & 3.37 & 0.080 & 0.12 \\
\hline $\begin{array}{c}\text { Robust } \\
\text { cicada }\end{array}$ & 66.8 & 21.68 & 2.37 & 0.074 & 0.52 \\
\hline $\begin{array}{c}\text { Meimuna } \\
\text { mongolica }\end{array}$ & 66.9 & 21.33 & 2.81 & 0.062 & 0.34 \\
\hline
\end{tabular}

매미종보다 사람에게 불쾌감을 줄 수 있는 소리임을 확인했다. 한편, 변동강도(fluction strength)는 참매미 가 0.52 vacil로 가장 크게 나타났는데 이는 참매미가 울때 매-앰 매-앰 울면서 주기적으로 소리가 커지고 작아지기를 반복하기 때문이다. Table 4는 말매미, 참 매미, 쓰름매미 울음소리의 음질 값 계산 결과를 나 타낸다.

\section{6. 결 론}

이 연구에서는 도심지 주거지역 16 개 지점을 대상으로 여름철 매미 서식현황을 조사한 결과 말매미, 참매미, 쓰름매미가 서식하는 것으로 조 사되었으며, 말매미는 16 개 모든 조사지점에서 참 매미는 3 개 지점에서 쓰름매미는 1 개 지점에서 서식하는 것을 확인하였다. 주.야간 매미종에 따 른 울음소리 크기를 조사한 결과, 매미 울음소리 는 말매미, 쓰름매미, 참매미 순으로 큰 것으로 나타났으며, 특히 야간에도 옥외 조명으로 주변 환경이 밝은 지역에서는 매미가 우는 것으로 조 사되었다. 매미 종별로 울음소리에 대한 주파수 분석 및 시간-주파수 분석 결과, 말매미 울음소리 는 $4 \mathrm{kHz}$ 이상의 주파수 성분이 커 샤프니스가 크게 나타났고, 참매미와 쓰름매미는 시간에 따른 소음 크기 및 주파수 성분이 주기적을 변하여 변 동강도가 큰 것으로 나타났다. 매미 종별로 음질 분석 결과, 말매미는 라우드니스, 샤프니스, 러프 니스가 가장 크게 나타나 소리가 가장 크기도 하 지만 날카로우며 거칠어 사람에게 가장 불쾌감을 줄 것으로 판단되며, 향후 이들 매미 울음소리에 
대한 음질 분석 결과는 추후 매미 소음이 사람에 게 주는 불쾌감 또는 짜증도 규명 시 기초자료로 활용이 기대된다.

\section{참 고 문 헌}

(1) Fahy, F. and Walker, J., 1998, Fundamentals of Noise and Vibration, Routledge, London.

(2) Zwicker, E. and Fastl, H., 1990, Psycho- acoustics, Facts and Models, Springer-Verlag, Berlin, pp. 220, 242, 256, 263.

(3) Oran Brigham, E., 1988, The Fast Fourier Transform and Its Applications, Prentice-Hall, Prentice-Hall, New Jersey.

(4) DiLaura, D. L., Houser, K. W., Mistrick, R. G. and Steffy, G. R., 2011, The Lighting Handbook, Tenth Edition, Illuminating Engineering Society, New York. 